\title{
Mortality differences by parental social class from childhood to adulthood
}

\author{
Tiina H Pensola, Tapani Valkonen
}

\begin{abstract}
Study objective-To examine mortality differences by parental social class and cause of death from age 5 to age 34 .

Design-Register-based follow up study based on census records for 1985 and 1990 linked with death records for the period 1987-95.

Setting and subjects-The study covers all males and females in non-manual and manual classes in Finland aged 5-34 years in 1987-95 (8135 deaths). Parental social class is defined on the basis of the occupation of the head of household at the time the child was $0-14$ years.

Main outcome measures-All cause mortality, mortality from diseases, mortality from accidents and violence, and alcohol related mortality during the period 198795.

Main results-At ages 5-14 there is no systematic gradient in mortality by parental social class. Both absolute and relative differences increase with age. The relative rate of male all cause mortality among manual class descendants at ages 25-29 compared with that of upper non-manual class descendants is $1.60(95 \%$ CI 1.37 , 1.86). At ages $30-34$ the relative rate among males is 1.95 (95\% CI 1.58, 2.42) and among females 1.47 (95\% CI 1.03, 2.10). Among males alcohol related causes of death account for $70 \%$ of the excess mortality of sons of manual class parents compared with sons of upper non-manual class parents at ages 25-34. At ages 25-34, both among females and males, the contribution of diseases to the mortality difference increases.

Conclusions-Parental social class has an impact on mortality after childhood mainly through health related behaviours and lifestyles up to age 34 .

(7 Epidemiol Community Health 2000;54:525-529)
\end{abstract}

Results from studies on socioeconomic mortality differences among adults have consistently shown a clear rising gradient of mortality from high to low socioeconomic positions. ${ }^{1-5}$ On the other hand, the results from the few studies $^{6-11}$ concerning social variation in mortality from childhood to adulthood are inconsistent. Rimpelä ${ }^{6}$ found no differences in total mortality among females aged 5-24 in Finland and only minor differences among males under age 20. Östberg ${ }^{10}$ and Östberg and Vågerö ${ }^{11}$ concluded that there were wide relative differences in total mortality between social classes at ages 1-19 in Sweden, whereas $\mathrm{West}^{78}$ concluded that the differences were very narrow in the age group 10-14 in England and Wales. Blane and colleagues ${ }^{9}$ found no class differences in mortality from diseases in this age group in England and Wales.

Some of the discrepancies discovered in earlier studies in the association between childhood class and mortality may be attributable to the limited number of deaths in some of these studies, leading to very wide confidence limits for death rates. ${ }^{912}{ }^{13}$ Earlier research has also been marred by the unsystematic measurement of social class. Many young persons cannot yet be assigned to a social class on the basis of their occupation because they are either studying or unemployed, and for many of those who have an occupation, occupational status is transient. ${ }^{14}$ Because of these difficulties children under 16 have been classified on the basis of parental class, while those over 16 have usually been assigned to their own class. Those who as yet have no occupation are either left in the category of unknown ${ }^{8}$ or classified on the basis of parental class. ${ }^{6}$ However, it is important to have a uniform definition of social class within and between age groups to avoid apparent changes in class patterning of mortality attributable to different classifications. The system of personal identification numbers that is in use in Finland means it is possible to follow the mortality of the whole population by social class. Although death rates are very low at young ages, the large number of persons and the long follow up period allow us to study mortality even by certain main categories of causes of death. Our data also allow for uniform measurement of socioeconomic position for all young persons up to age 34 . The following questions are investigated in this paper:

(1) To what extent do there occur systematic social class differences in all cause mortality by parental class in different age groups at ages from 5 to 34 ?

(2) What is the class patterning of mortality by age and cause of death?

(3) What causes of death account for the class difference in mortality between nonmanual and manual classes in different age groups?

\section{Methods}

The data used in this study were extracted from two data files compiled by Statistics Finland. The first one is based on the 1985 census records for persons born in 1956-85. The death records for 1986-90 and socioeconomic information from the censuses of 1970, 1975 and 1980 were linked to the records by means of personal identification numbers. The second data file consists of the 1990 census records, 
Table 1 Distribution of person years (\%) covered by the study by age and parental social class

\begin{tabular}{|c|c|c|c|c|c|c|c|c|}
\hline \multirow[b]{2}{*}{ Age } & \multicolumn{8}{|c|}{ Parental social class } \\
\hline & $\begin{array}{l}\text { Upper } \\
\text { non-manual }\end{array}$ & $\begin{array}{l}\text { Lower } \\
\text { non-manual }\end{array}$ & Manual & Farmer & Entrepreneur & Other & All & $\begin{array}{l}\text { Person years } \\
(1000 s)\end{array}$ \\
\hline $5-9$ & 20 & 24 & 38 & 6 & 7 & 5 & 100 & 2874 \\
\hline $10-14$ & 20 & 26 & 38 & 7 & 8 & 2 & 100 & 2904 \\
\hline $15-19$ & 19 & 25 & 40 & 7 & 7 & 2 & 100 & 2829 \\
\hline $20-24$ & 15 & 22 & 45 & 9 & 6 & 2 & 100 & 3025 \\
\hline $25-29$ & 12 & 18 & 45 & 15 & 7 & 3 & 100 & 3329 \\
\hline $30-34$ & 10 & 16 & 44 & 18 & 7 & 5 & 100 & 1888 \\
\hline
\end{tabular}

which were linked to the death records for 1991-95 and the census records for 1970, 1975, 1980 and 1985 for persons born in 1956-90. The analyses cover person years and deaths in ages from 5 to 34 during 1987-95 in the two data files.

In Finnish censuses economically non-active children living at home are assigned to socioeconomic classes on the basis of the occupation of the head of household. In this study parental social class refers to the class of the head of household in the census where the person was 10-14 years of age. In the birth cohorts younger than 10 years of age in the 1985 or 1990 census, parental social class is based on the information in that census. For approximately $7 \%$ of the study population parental class was unknown in the most relevant census; for these people the information was obtained, if possible, from the preceding census.

The classification of parental class used in this study is based on Statistics Finland's classification of socioeconomic classes. $^{3}{ }^{15}$ Table 1 shows the distribution of the person years covered by the dataset by parental social class. There are some differences between the age groups that are attributable to changes in the occupational structure of the population. The following categories are used in the study:

(1) Upper non-manual class (for example, managers and higher administrative or clerical workers).

(2) Lower non-manual class (for example, lower administrative or clerical workers).

(3) Manual class.

Farmers, entrepreneurs and others have been excluded from the analyses because they form small but heterogeneous groups that are

Table 2 Number of deaths in five year age groups from diseases, and accidental and violent deaths by relation to alcohol. Females and males in non-manual and manual classes aged 5-34 in 1987-1995

\begin{tabular}{|c|c|c|c|c|c|c|c|c|c|}
\hline & \multicolumn{4}{|c|}{ Females } & \multicolumn{4}{|l|}{ Males } & \\
\hline & \multicolumn{8}{|c|}{ Cause of death } & \\
\hline & \multicolumn{2}{|c|}{ Diseases } & \multicolumn{2}{|c|}{$\begin{array}{l}\text { Accidents } \\
\text { and violence }\end{array}$} & \multicolumn{2}{|c|}{ Diseases } & \multicolumn{2}{|c|}{$\begin{array}{l}\text { Accidents } \\
\text { and violence }\end{array}$} & \multirow[b]{3}{*}{ All } \\
\hline & \multicolumn{8}{|c|}{ Alcohol related underlying or contributing cause of death ${ }^{\star}$} & \\
\hline & no & yes & no & yes & no & yes & no & yes & \\
\hline \multicolumn{10}{|c|}{ Age group } \\
\hline $5-9$ & 115 & 0 & 52 & 0 & 112 & 0 & 125 & 0 & 404 \\
\hline $10-14$ & 101 & 0 & 67 & 3 & 112 & 1 & 135 & 8 & 427 \\
\hline $15-19$ & 116 & 2 & 194 & 55 & 171 & 2 & 561 & 332 & 1433 \\
\hline $20-24$ & 166 & 6 & 205 & 61 & 246 & 18 & 738 & 624 & 2064 \\
\hline $25-29$ & 238 & 14 & 200 & 75 & 313 & 51 & 704 & 714 & 2309 \\
\hline $30-34$ & 197 & 13 & 98 & 43 & 283 & 90 & 355 & 419 & 1498 \\
\hline All & 933 & 35 & 816 & 237 & 1237 & 162 & 2618 & 2097 & 8135 \\
\hline
\end{tabular}

ॠThe following are defined as alcoholic causes: 265.0A, 291, 303, 305, 375.5, 425.5, 535.3, 571.0-571.3, 577.0D-F, 577.1C-D, E849 and E851. impossible unequivocally to slot in the socioeconomic hierarchy.

Causes of death were coded according to the Finnish Classification of Diseases $1987,{ }^{16}$ which is based on the Ninth Revision of the International Classification of Diseases but which uses five digit instead of four digit codes. For this study deaths were first classified by cause into two groups: diseases (1-799) and accidental and violent causes (E800-999), and then within these groups into alcohol related and non-alcohol related deaths. The definition of alcohol related death is the same as that used by Mäkelä et al. ${ }^{17}$

Alcohol related deaths are those in which either the underlying cause of death explicitly mentions alcohol or in which the underlying cause does not mention alcohol, but at least one of three possible contributory causes is either alcoholic intoxication or one of the causes of death explicitly mentioning alcohol, such as alcoholic psychoses, alcoholic diseases of the liver, alcoholic diseases of the pancreas, accidental poisoning by alcohol and accidental poisoning by medicinal agents in combination with alcohol (see table 2).

Person years and deaths by cause of death were tabulated by parental social class and period (1987-90 and 1991-95). Statistical analyses were based on the Poisson regression model, with the cell in cross tabulation taken as the unit of analysis. The GLIM statistical package $^{18}$ was used in fitting the models. The results are presented as relative mortality rates (and their 95\% confidence intervals). The reference group is children in the upper nonmanual class. Tests for gradients of period adjusted rates were obtained by the Poisson regression model in GLIM with period and social class (coded from one to three and used as continuous variable) as covariates.

As the summary measure that adjusts for the differences among age groups in the occupational structure, we have used the relative index of inequality (RII). ${ }^{19}$ Poisson regression was used to estimate the slopes.

\section{Results}

Table 2 gives the numbers of deaths by age, sex and cause of death. The number of alcohol related deaths from diseases is low, and therefore in the remaining analyses all alcohol related deaths are analysed as one group.

Figure 1 presents the relative death rates in all cause mortality and for three groups of causes of death by parental social class and age for females and males. In all cause mortality 

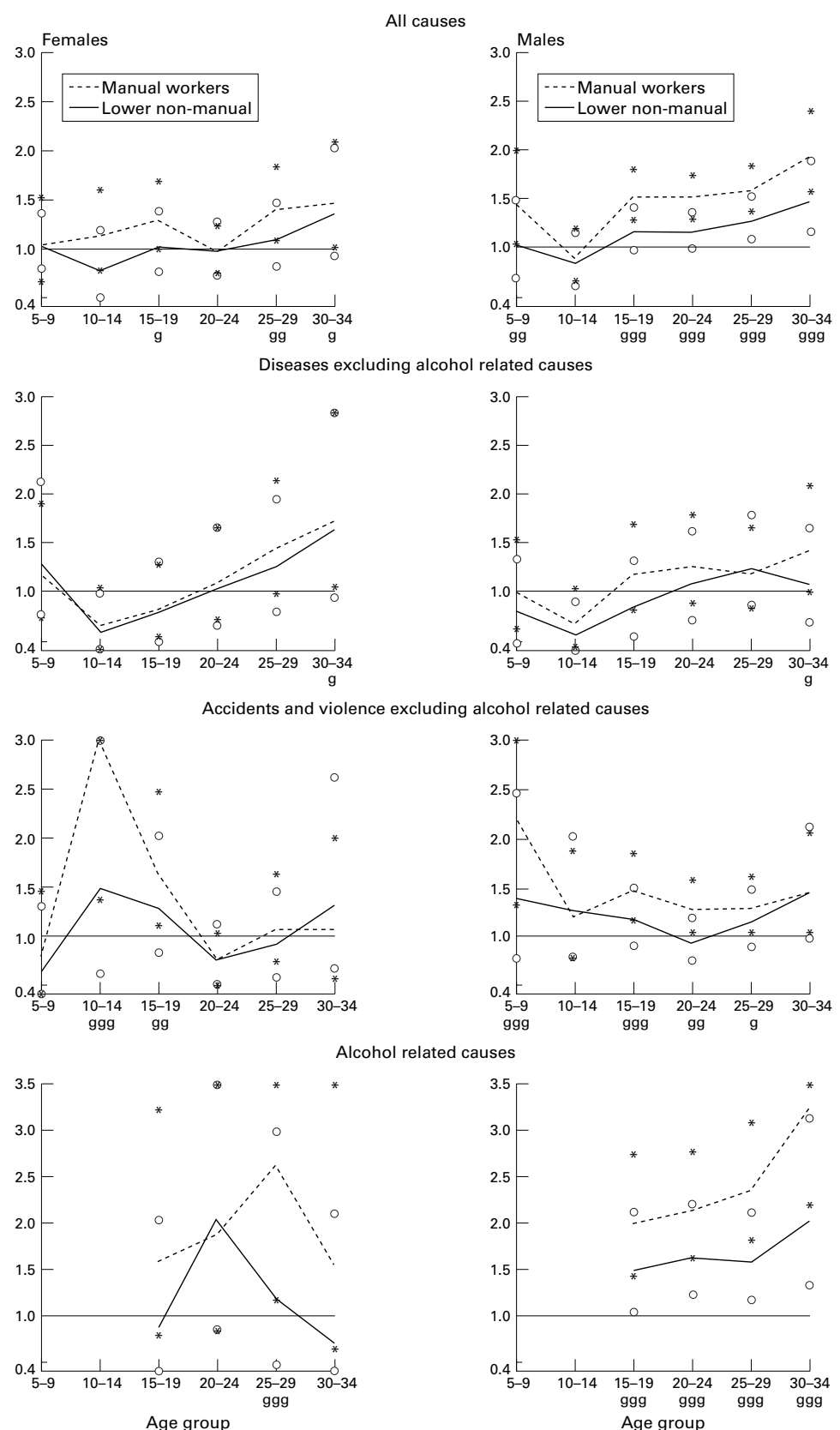

Alcohol related causes

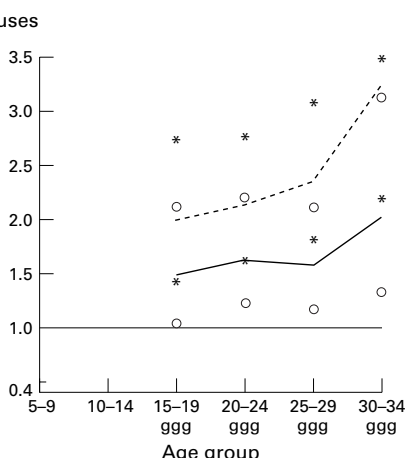

Figure 1 Relative death rates in all cause mortality, and in three causes of death by age (five year age groups) and parental social class 1987-95, females and males (children of upper non-manual class $=1)$. $o=95 \%$ CI for lower non-manual employees. ${ }^{*}=95 \% \mathrm{CI}$ for manual workers. Statistically significant gradients: $g=p<0.05, g g=p<0.01, \operatorname{ggg}=p<0.001$.

there is a statistically significant mortality gradient among women at ages $15-19$ and 25-34 and among males in all age groups except $10-14$.

Disease mortality among children of the upper non-manual class is higher than among children of lower non-manual and manual classes at ages 10-19 among females, and at ages 5-14 among males, but the differences are statistically insignificant. After age 20 descendants of manual and lower non-manual classes show a higher mortality than the reference group, but the mortality gradient is statistically significant only at ages 30-34.

In mortality from accidental and violent causes excluding alcohol related deaths, daughters of manual class parents show a statistically

significant excess mortality only at ages $10-19$. Sons of manual class parents have statistically significant excess mortality compared with sons of upper non-manual class in all age groups except 10-14.

Among males the clearest differences in mortality by parental social class are found in alcohol related deaths. These statistically significant differences increase with age.

Table 3 shows the absolute mortality differences and the contribution of selected causes of death to the total absolute difference between manual and upper non-manual, and between lower and upper non-manual classes. Among females the differences between upper nonmanual and other classes are small. For them the differences in disease mortality have the greatest impact on the total difference at ages 30-34. Among males the contribution of accidents and violence without alcohol related causes to the mortality difference between manual and upper non-manual class declines with increasing age. The impact of diseases is quite minor, while alcohol related causes are predominant in all age groups in both comparisons. At ages $25-34$ approximately $70 \%$ of the difference between the manual and upper nonmanual class and $60 \%$ of the difference between the upper and lower non-manual class can be attributed to alcohol related causes.

According to table 1 the distribution of parental class is different in young and old age groups. Table 4 shows an estimate of the extent to which this difference affects the results. The table first presents the strength of the association between parental class and mortality for five year age groups by using the adjusted RII, which eliminates the effect of the differences between the age groups in the distribution of parental class. The "non-adjusted" $\mathrm{RII}^{\star}$ is calculated on the basis of the assumption that the parental class distribution is the same in all age groups as in the age group 20-24. The comparison shows only minor differences between the two columns (RII and RII ${ }^{\star}$ ), indicating that the differences in the distribution of parental class have no more than a minimal effect on the results. 
Table 3 Absolute difference in all cause mortality between descendants of (1) manual and upper non-manual classes, and (2) lower and upper non-manual classes, and per cent of ${ }^{\star}$ the difference accounted for by three groups of causes of death by age, females and males

\begin{tabular}{|c|c|c|c|c|c|c|c|c|c|c|}
\hline \multirow[b]{4}{*}{ Age } & \multicolumn{10}{|c|}{ Absolute difference between descendants of } \\
\hline & \multicolumn{5}{|c|}{ (1) manual and upper non-manual classes } & \multicolumn{5}{|c|}{ (2) lower and upper non-manual classes } \\
\hline & \multirow[b]{2}{*}{$\begin{array}{l}\text { Total } \\
\text { difft }\end{array}$} & \multicolumn{4}{|c|}{$\%$ of difference accounted for by } & \multirow[b]{2}{*}{$\begin{array}{l}\text { Total } \\
\text { difft }\end{array}$} & \multicolumn{4}{|c|}{$\%$ of difference accounted for by } \\
\hline & & Diseases $\neq$ & $\begin{array}{l}\text { Accidents } \\
\text { and violence } \neq\end{array}$ & $\begin{array}{l}\text { Alcohol } \\
\text { related }\end{array}$ & Total & & Diseases $\neq$ & $\begin{array}{l}\text { Accidents } \\
\text { and violence } \neq\end{array}$ & $\begin{array}{l}\text { Alcohol } \\
\text { related }\end{array}$ & Total \\
\hline \multicolumn{11}{|l|}{ Females } \\
\hline $5-9$ & 0.2 & - & - & - & - & 0.1 & - & - & - & - \\
\hline $10-14$ & 1.6 & - & - & - & - & -3.3 & - & - & - & - \\
\hline $15-19$ & 8.7 & -23 & 95 & 28 & 100 & 0.7 & - & - & - & - \\
\hline $20-24$ & -1.3 & - & - & - & - & -1.4 & - & - & - & - \\
\hline $25-29$ & 13.6 & 47 & 11 & 42 & 100 & 2.8 & - & - & - & - \\
\hline $30-34$ & 18.5 & 74 & 6 & 20 & 100 & 14.3 & 83 & 31 & -13 & 100 \\
\hline \multicolumn{11}{|l|}{ Males } \\
\hline $5-9$ & 7.4 & -2 & 102 & 0 & 100 & 0.3 & - & - & - & - \\
\hline $10-14$ & -2.4 & - & - & - & - & -3.7 & - & - & - & - \\
\hline $15-19$ & 36.7 & 6 & 48 & 46 & 100 & 12.5 & -17 & 50 & 67 & 100 \\
\hline $20-24$ & 51.2 & 9 & 28 & 63 & 100 & 16.3 & 8 & -21 & 113 & 100 \\
\hline $25-29$ & 58.4 & 7 & 22 & 72 & 100 & 28.5 & 17 & 22 & 61 & 100 \\
\hline $30-34$ & 95.0 & 15 & 18 & 67 & 100 & 48.1 & 4 & 34 & 62 & 100 \\
\hline
\end{tabular}

$\star$ Per cent of the difference accounted for by the cause of death category: $\left(\left(\mathrm{mr}_{\mathrm{i}}^{\mathrm{c}}-\mathrm{mr}_{\mathrm{i}}^{\mathrm{r}}\right) /\left(\mathrm{MR}^{\mathrm{c}}-\mathrm{Mr}^{\mathrm{r}}\right)\right)^{\star} 100$, where $\mathrm{mr}_{\mathrm{i}}=\mathrm{mortality}$ rate in cause $i, M R=$ mortality rate in all causes, $c=$ comparison group, $r=$ upper non-manual class. $\dagger$ Deaths per 100000 person years. ‡Excluding alcohol related deaths. - Total difference is too small to be divided meaningfully into different causes of death.

Table 4 Relative index of inequality (RII) and "non-adjusted" relative index of inequality (RII*) for all cause mortality among descendants of upper and lower non-manual classes and manual class, females and males

\begin{tabular}{llllll}
\hline & \multicolumn{3}{l}{ Females } & & \multicolumn{2}{l}{ Males } \\
\cline { 2 - 3 } \cline { 5 - 6 } Age & RII & RII & & RII & RII* \\
\hline $5-9$ & 1.0184 & 1.0181 & & 1.9544 & 1.9666 \\
$10-14$ & 1.3562 & 1.3970 & & 0.8854 & 0.8971 \\
$15-19$ & 1.6152 & 1.6253 & & 1.9666 & 1.9672 \\
$20-24$ & 0.9620 & 0.9620 & & 1.9480 & 1.9480 \\
$25-29$ & 1.7657 & 1.7618 & & 1.9192 & 1.9270 \\
$30-34$ & 1.5274 & 1.5488 & & 2.4006 & 2.4344 \\
\hline
\end{tabular}

*The $\mathrm{RII}^{\star}$ was calculated on the assumption that the distribution of parental class in all age groups was the same as that in the age group $20-24$ years.

\section{Discussion}

DISEASE MORTALITY

Our findings on the non-existence of differences in disease mortality for females under age 20 are consistent with the results for Britain ${ }^{9}$ and for Sweden in 1961-79, ${ }^{11}$ but in 1981-86 Swedish females aged 1-19 with a manual class background showed statistically significant excess mortality. ${ }^{10}$ Our results concerning males under age 20 differ from the results for both Sweden and Britain. In Sweden in $1961-79^{11}$ sons of manual workers and in $1981-86,{ }^{10}$ sons of unskilled workers showed higher mortality than sons of non-manual workers. In Britain there was a gradient in mortality at ages $0-9$ but not at ages $10-14 .{ }^{9}$

In older age groups our results are consistent with the results for Sweden ${ }^{11}$ and the results for Britain for males, ${ }^{9}$ but in Britain females aged 15-29 showed higher disease mortality in the non-manual than the manual class. The differences observed between our results and those from Britain and Sweden may reflect real differences between the countries, but it is also possible that the differences between Finland and Britain are attributable to chance variation. The number of deaths covered by the British study was small (304 deaths at ages 0-29) and none of the gradients reported were statistically significant.
ACCIDENTS AND VIOLENCE

In accidental and violent deaths daughters of manual class parents show excess mortality at ages 10-19 and sons at ages 5-9 and 15-34, when alcohol related causes are excluded, compared with children from an upper nonmanual class background. In the Swedish studies mentioned above ${ }^{1011}$ the results were essentially the same. In England and Wales in 1985-92, children of manual workers aged $0-14$ showed excess mortality in every accidental and violent cause category. ${ }^{20}$

\section{ALCOHOL RELATED DEATHS}

Earlier Finnish studies ${ }^{17}{ }^{21}$ have highlighted the role of alcohol in the mortality difference between both social classes and genders in adulthood. In this study the exclusion of alcohol related causes at ages 15-34 would reduce the mortality differences by parental social class; in some cases the differences would disappear almost completely.

In this study the information on alcohol related deaths comes mainly from contributory causes of death; in the age groups concerned alcohol is mentioned as an underlying cause of death in only $22 \%$ of females and $14 \%$ of males with an alcohol related cause of death. It is not clear how far these results can be generalised to other countries because earlier studies have not made use of data on contributory causes of death. Some insight is gained by comparing mortality attributable to accidental and violent deaths in Finland in 1989-91 to mortality in nine West European countries where data were available for about the same period. ${ }^{22-24}$ For males aged 15-24, Switzerland was the only country where mortality attributable to accidents and violent causes was as high as in Finland; in all other countries, and in all countries at ages $25-34$, it was much lower (for example, in France 25\%, in Sweden $44 \%$ and in the United Kingdom $60 \%$ lower than in Finland; for females the corresponding figures were $1 \%$, $12 \%$ and $47 \%$ ). It seems probable that both the 
high male mortality from accidents and violence and the observed major contribution of alcohol related deaths to the class difference in mortality among young men is attributable to the high level of alcohol related accidents in Finland.

The predominant role of alcohol related mortality underscores the importance of health behaviours and life styles in explaining mortality differences in young adulthood in Finland. To reduce class differences in mortality and in general to reduce mortality among young persons, it is imperative that action is taken to encourage teenagers in different groups to change their drinking habits.

\section{ALL CAUSE MORTALITY}

In the youngest age groups studied here mortality is low and the absolute differences are small. Earlier studies in Sweden ${ }^{10}$ and Britain ${ }^{25}$ have reported excess mortality in children from a manual class background compared with children of non-manual class parents.

An issue of concern, as Judge and Benzeval ${ }^{26}$ have shown for Britain, is the group of "others". In our data "others" is so small a group that their inclusion in the manual class would have only a minor impact on the results. Thus, at least in Finland, small mortality differences at ages 5-14 are not a result of incomplete data. They may, however, be attributable to the low mortality in this age group. During the first year of life, when the probability of death among males is eight times and among females six times greater than the probability of death at ages $5-14,{ }^{3}$ mortality rates between manual and non-manual classes do differ. ${ }^{6}{ }^{27-30}$

West ${ }^{7}$ has argued that if the size of mortality differences changed with age among young persons, the conclusions we would need to draw about the causes of socioeconomic mortality differences would be different than if the gradient were found to be the same in all age groups. The latter possibility suggests causal $^{31}$ and the former both causative and selective explanations. ${ }^{8}$ Our results lend support to West's ${ }^{78}$ conclusion that youth is characterised by relative equality of health, but not to his suggestion that mortality differences diminish in adolescence after greater inequalities in mortality in childhood. Nevertheless a class gradient in all cause mortality is found after age group 20-24 among females and among males 15 on, as West ${ }^{7}{ }^{8}$ has suggested.

In this study the class differences at ages 15-34 were smaller than in an earlier Finnish study ${ }^{3}$ for the period $1986-90$, in which social class was based principally on own occupation. The greater mortality differences based on own occupation might partly be attributable to social mobility, involving direct and indirect health selection.
Funding: we are indebted to the Academy of Finland (grant 41498) for funding the study and to Statistics Finland for granting access to the data set (permission TK 53-1783-96).

Conflicts of interest: none.

1 Townsend P, Davidson N. Inequalities in health. Harmondsworth: Penguin Books, 1982.

2 Marmot M, Shipley $M$, Rose G. Inequalities in deathspecific explanations of a general pattern? Lancet 1984;i: 1003-6.

3 Valkonen T, Martelin T, Rimpelä A, et al. Socio-economic mortality differences in Finland 1981-90. Helsinki: Statistics Finland, 1993.

4 Mackenbach J, Kunst A, Cavelaars A, et al. Socioeconomic inequalities in morbidity and mortality in western Europe. Lancet 1997;349:1655-9.

5 Kunst A. Cross-national comparisons of socio-economic differences in mortality. [ PhD thesis]. Rotterdam: Erasmus Uniences in mortality.

6 Rimpelä A. Children. Adolescents and young adults. In: Valkonen T, Martelin T, Rimpelä A, et al. Socio-economic mortality differences in Finland. Helsinki: Statistics Finland 1993:20-32.

7 West P. Inequalities? Social class differentials in health in British youth. Soc Sci Med 1998;27:291-6.

8 West P. Health inequalities in the early years: is there equalisation in youth? Soc Sci Med 1997;44:833-58.

9 Blane D, Bartley M, Davey Smith G, et al. Social patterning of medical mortality in youth and early adulthood. Soc $S c i$ Med 1994;39:361-6.

10 Östberg V. Social class differences in child mortality, Sweden 1981-86. I Epidemiol Community Health 1992;46: 480-4.

11 Östberg V, Vågerö D. Socio-economic differences in mortality among children. Do they persist into adulthood? Soc Sci Med 1991;32:403-10.

12 Lynch J, Kaplan G, Cohen R, et al. Childhood and adult socioeconomic status as predictors of mortality in Finland. Lancet 1994;343:524-7.

13 Peck Nyström M. Childhood environment, intergenerational mobility and adult health-evidence from Swedish data. F Epidemiol Community Health 1992;46:71-4.

14 Goldthorpe J. Social mobility and class structure in modern Britain. Oxford: Clarendon Press 1980

15 Statistics Finland. Classification of socio-economic status. Handbooks no 17. Helsinki: Statistics Finland, 1989.

16 National Bord of Health. Tautiluokitus 1987, osa1, systemaattinen osa. Helsinki: Lääkintöhallitus 1986.

17 Mäkelä P, Valkonen T, Martelin T. Contribution of deaths related to alcohol use tosocioeconomic variation in mortality: register based follow up study. BMF 1997;315: $211-16$

18 Francis B, Green M, Payne C, ed. The Glim System. Release 4 manual. Oxford: Clarendon Press, 1993.

19 Mackenbach J, Kunst A. Measuring the magnitude of socioeconomic inequalities in health: an overview of available measures illustrated with two examples from Europe. Soc Sci Med 1997;44:757-71.

20 Roberts I. Cause specific social class mortality differentials for child injury and poisoning in England and Wales. $\mathcal{F}$ Epidemiol Community Health 1997;51:334-5.

21 Mäkelä P. Alcohol-related mortality by age and sex and its impact on life expectancy: estimates based on the Finnish Death Register. Eur f Public Health 1998;8:43-51.

22 World Health Organisation. World Health Statistics Annual 1990. Geneva: WHO, 1991.

23 World Health Organisation. World Health Statistics Annual 1991. Geneva: WHO, 1992.

24 World Health Organisation. World Health Statistics Annual 1992. Geneva: WHO, 1993

25 Botting B. Mortality in childhood. In: Drever F, Whitehead $\mathrm{M}$, ed. Health inequalities. London: The Stationery Office, 1997:83-94.

26 Judge K, Benzeval M. Health inequalities: new concerns about the children of single mothers. BMF 1993;306:67780.

27 Notkola V, Savela S. Infant mortality and still births. In: Valkonen T, Martelin T, Rimpelä A, et al. Socio-economic mortality differences in Finland 1981-90. Helsinki: Statistics Finland 1993:17-19.

28 Notkola V, Valkonen T. Socioeconomic differences in stillbirths and infant mortality. Yearbook of Population stillbirths and infant mortality. Yearbook of Population Institute, 1989.

29 Leon DA, Vågerö D, Olausson PO. Social class differences in infant mortality in Sweden: comparison with England and Wales. BMF 1992;305:687-91.

30 Arnzten A, Moum T, Magnus P, et al. Is the higher postneonatal mortality in lower social status groups due to SIDS? Acta Paediatr 1995;84:188-92.

31 West P, Macintyre S, Annadale E, et al. Social class and health in youth: findings from the west of Scotland twenty-07 study. Soc Sci Med 1990;30:665-73. 